\title{
EFFECT OF COOLING RATE AND AGING ON MICROSTRUCTURE AND TENSILE PROPERTIES OF TC21 TITANIUM ALLOY.
}

\author{
Ibrahim, K. M. ; Barakat, A. F. '; Elshaer, R. N. ${ }^{*} \S$ and Abbas, R. R. ${ }^{\dagger}$ \\ * Central Metallurgical $R \&$ D Institute, Cairo, Egypt. \\ ${ }^{\dagger}$ Faculty of Engineering, Helwan University, Cairo, Egypt. \\ §Ramadan_elshaer@yahoo.com
}

\begin{abstract}
Effect of cooling rate and aging treatment on microstructure and tensile properties of TC21 titanium alloy was investigated. The samples were solution treated at $900^{\circ} \mathrm{C}$ for 15 min followed by cooling either/ water quenching (WQ) or air cooling (AC). Consequently, aging treatment was applied at $575^{\circ} \mathrm{C}$ for $4 \mathrm{hr}$. The results showed that heat-treatment parameters (cooling rate and aging treatment) had influence the feature and content of $\alpha$ phase, $\beta$ phase and secondary $\alpha$ phase. Optimum heat treatment process of TC21 titanium alloy was obtained by treatment at $900^{\circ} \mathrm{C} / 15 \mathrm{~min} / \mathrm{AC}+575^{\circ} \mathrm{C} / 4 \mathrm{hr} /$ AC. Under this treatment condition, better combination of hardness and tensile properties was achieved.
\end{abstract}

Keywords: TC21 titanium alloy; cooling rate; aging; microstructure; tensile properties.

\section{INTRODUCTION}

Titanium alloys, especially $\alpha+\beta$ titanium alloys are widely used as structural components in advanced aerospace applications and aero-engines due to their light weight, high strength, high fracture toughness, corrosion resistance, low Young's modulus, and non-toxicity. Titanium alloys have become one of the indispensable structure materials for airplanes. They are used in advanced airplanes to $30 \%-50 \%$ weight of the total structure, for instance, $41 \%$ in F-22 fighters [1-4]. The mechanical properties of titanium alloys are strongly correlated to their microstructures that can be developed during thermomechanical processing and final heat treatments [5]. Usually, equiaxed microstructure after processing or heat treatment in the two-phase field has advantages in terms of ductility and high cycle fatigue property. While, in a singlephase field is characterized by high strength, fracture toughness and creep properties [6].

A new $\alpha+\beta$ titanium alloy, referred to as ultra-high strength TC21titanium alloy, with a nominal chemical composition of Ti-6Al-2Sn-2Zr-3Mo-1.5Cr-2Nb-0.1Si (wt.\%), has high strength, high toughness, low crack propagation rate and high damage tolerance and provides weight reduction, long service life, and high reliability in fabricated aircraft structural components such as frames and beams $[2,7]$.

With an appropriate heat treatment technique, TC21 alloy can obtain a better combination of tensile property, fracture toughness, and low fatigue crack growth rate, whose overall performance and engineering application value are better than the widely used traditional titanium alloy Ti6Al4V [8]. It has an increased room temperature 
strength ( $>1100 \mathrm{MPa}$ ) [9] compared with Ti6A14V. TC21 titanium alloy with excellent characteristics is expected to replace Ti6Al4V that is the most widely used at present. Therefore, it is important to know more about the microstructure and mechanical properties of TC21 titanium alloy. The solution and aging treatment have been chosen to optimize the microstructure and mechanical properties of TC21 titanium alloy by changing solution temperatures and cooling methods after solution with the same aging treatment $[10,11]$.

Recently, a variety of studies on phase transformation $[12,13]$, deformation behavior $[14,15]$, thermomechanical processes [16], thermohydrogen treatment [17], Oxidation treatment [18] and fatigue behavior [19] of TC21 alloy can be found. However, the detailed examinations of the effect of cooling rate and aging treatment on tensile properties are rarely reported. Therefore, in the present work, the effects of applying two different cooling rates and aging treatment on the microstructure and tensile properties of TC21 titanium alloy have been investigated.

\section{EXPERIMENTAL WORK}

TC21 titanium alloy bar with a diameter of $7 \mathrm{~mm}$ was used in this work. The $\beta$ transus temperature was approximately $960^{\circ} \mathrm{C}$ by dilatation method. The chemical composition of the alloy analyzed by inductive coupled plasma-atomic emission spectrometry (ICPAES) is listed in table 1. Volume fractions and size of the different phases were measured using quantitative metallographic method using PC based image analyzer. The XRD patterns confirmed the presence of $\alpha$ and $\beta$ phase in the investigated TC21 alloy of as-received state and no other phases were detected (figure 1).

Table (1): Chemical composition of as-received TC21 titanium alloy (mass fraction, \%).

\begin{tabular}{ccccccc}
\hline $\mathrm{Al}$ & $\mathrm{Mo}$ & $\mathrm{Nb}$ & $\mathrm{Sn}$ & $\mathrm{Zr}$ & $\mathrm{Cr}$ & $\mathrm{Si}$ \\
\hline 6.5 & 3.0 & 1.9 & 2.2 & 2.2 & 1.5 & 0.09 \\
\hline $\mathrm{Fe}$ & $\mathrm{C}$ & & $\mathrm{N}$ & $\mathrm{H}$ & $\mathrm{O}$ & $\mathrm{Ti}$ \\
\hline 0.05 & 0.01 & & 0.01 & 0.001 & 0.07 & Bal. \\
\hline
\end{tabular}

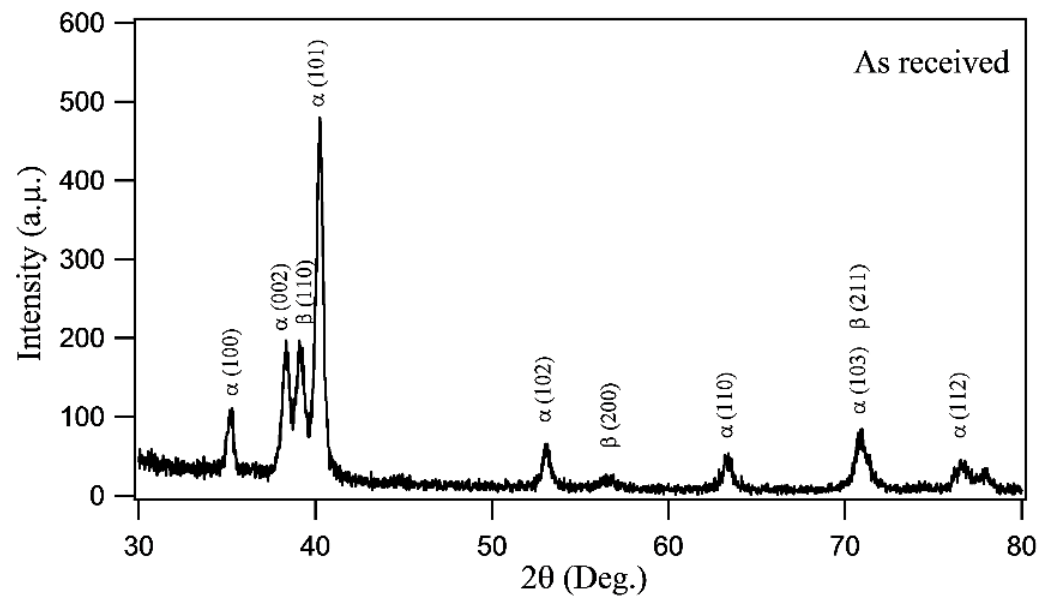

Fig. 1: XRD pattern of the as-received TC21 alloy. 
The samples were solution treated at $900^{\circ} \mathrm{C}$ for $15 \mathrm{~min}$ followed by either water quenching (WQ) or air cooling (AC). Consequently, aging treatment was carried out at $575^{\circ} \mathrm{C}$ for $4 \mathrm{hr}$. The samples for optical metallographic examination were prepared by mechanical polishing and then etching with a solution consisting of 3\% $\mathrm{HF}, 30 \% \mathrm{HNO}_{3}$ and $67 \% \mathrm{H}_{2} \mathrm{O}$. X-ray diffraction (XRD) analysis was conducted on finely polished samples to identify the present phases.

Hardness measurements were carried out using Vickers hardness tester apparatus (model 5030 SKV, England) in accordance to the ASTM E384-11 standard, with a load

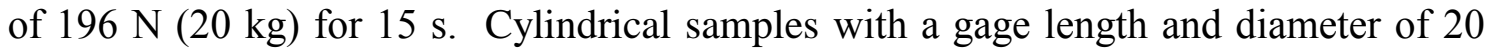
and $4 \mathrm{~mm}$, respectively, were machined for tensile testing according to ASTM E8-15 standard at room temperature using a strain rate of $0.5 \mathrm{~mm} / \mathrm{min}$, and the fractographic features of tensile samples were examined by field emission scanning electron microscope (FESEM).

\section{RESULTS AND DISCUSSION}

\subsection{As-received Microstructure}

The original microstructure of as-received TC21 titanium alloy consists mainly of primary equiaxed $\alpha$ phase and transformed $\beta$ matrix as shown in figure 2 . The average diameter of equiaxed $\alpha$ phase was approximately $2.5 \mu \mathrm{m}$ and their volume fraction approached to $65 \%$. The equiaxed $\alpha$ phase is distributed homogeneously in the entire field of view and fine $\alpha$ plates existing in the transformed $\beta$ matrix.

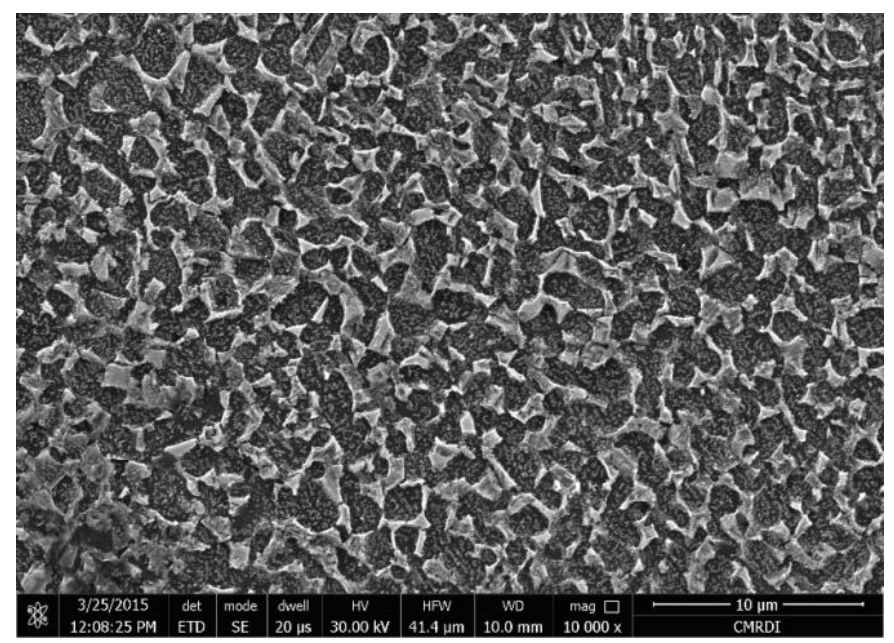

Fig. 2: FESEM micrograph of as-received TC21 titanium alloy bar.

\subsection{As-treated Microstructure}

\subsubsection{Effect of cooling condition}

The microstructures of solution treated TC21 samples followed by either WQ or AC are shown in figure 3. As seen from WQ condition (figure 3a), the volume fraction of $\alpha_{p}$ (primary equiaxed alpha phase) increases with the increase of cooling rate, retained $\beta$ phase does not decompose and the $\alpha_{\mathrm{s}}$ (secondary alpha phase) does not precipitate. In addition, the grain size of primary $\alpha$ phase for WQ is about $1.85 \mu \mathrm{m}$ and its volume 
fraction is about $70 \%$, and those increase to $2.05 \mu \mathrm{m}$ and decrease to $60 \%$, respectively, in the case of AC condition (figure $3 b$ ). Nevertheless, the secondary $\alpha$ phase occur at AC condition with the volume fraction about $29 \%$ because the amount of secondary $\alpha$ phase increases with prolonging cooling time. AC condition is considered as a fast cooling method for the TC21 alloy, because it does not produce a lamellar structure. Cooling rate in AC mainly affects the precipitation of the secondary $\alpha$ phase in the transformed $\beta$ phase. AC promotes the diffusion of atoms and nucleation of secondary $\alpha$ phase [20].

Based on the above discussion, the microstructure after AC condition consists of primary equiaxed $\alpha$ phase, secondary $\alpha$ phase and transformed $\beta$ phase. Whereas, the WQ condition consists of primary equiaxed $\alpha$ phase and transformed $\beta$ phase only. Each phase has been verified by X-Ray diffraction analysis, as shown in figure 4 .
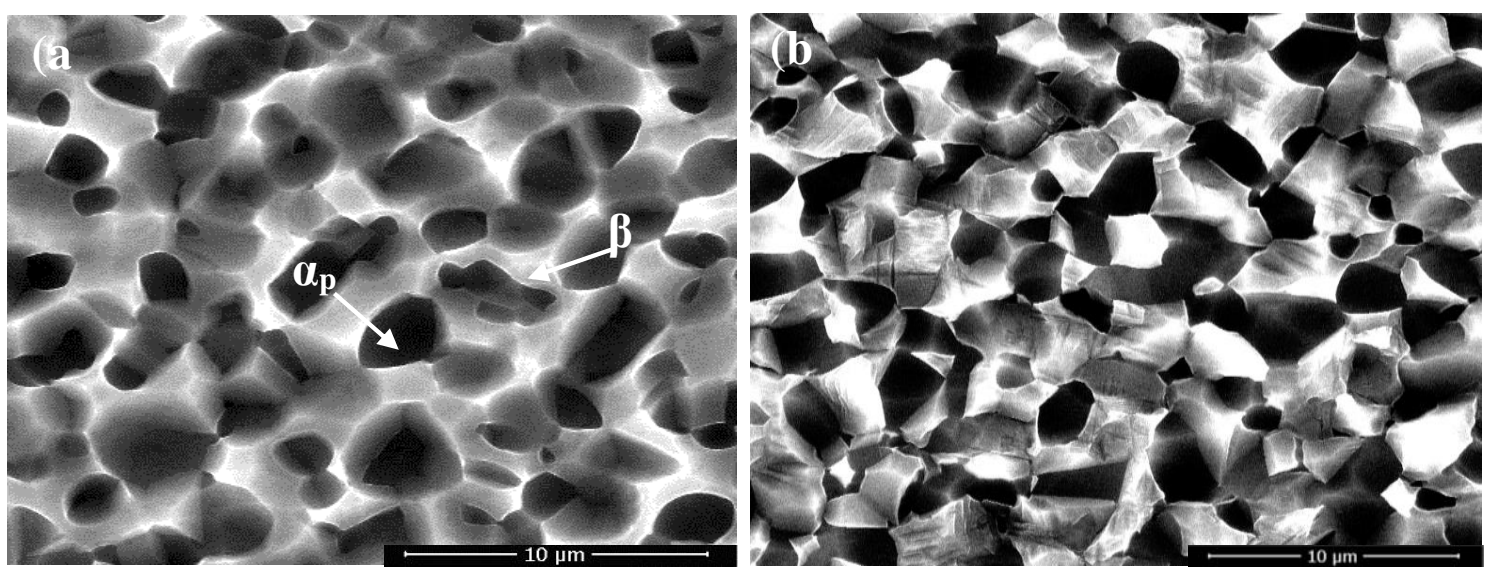

Fig. 3: FESEM micrographs showing the microstructures of the conditions: (a) WQ and (b) AC.

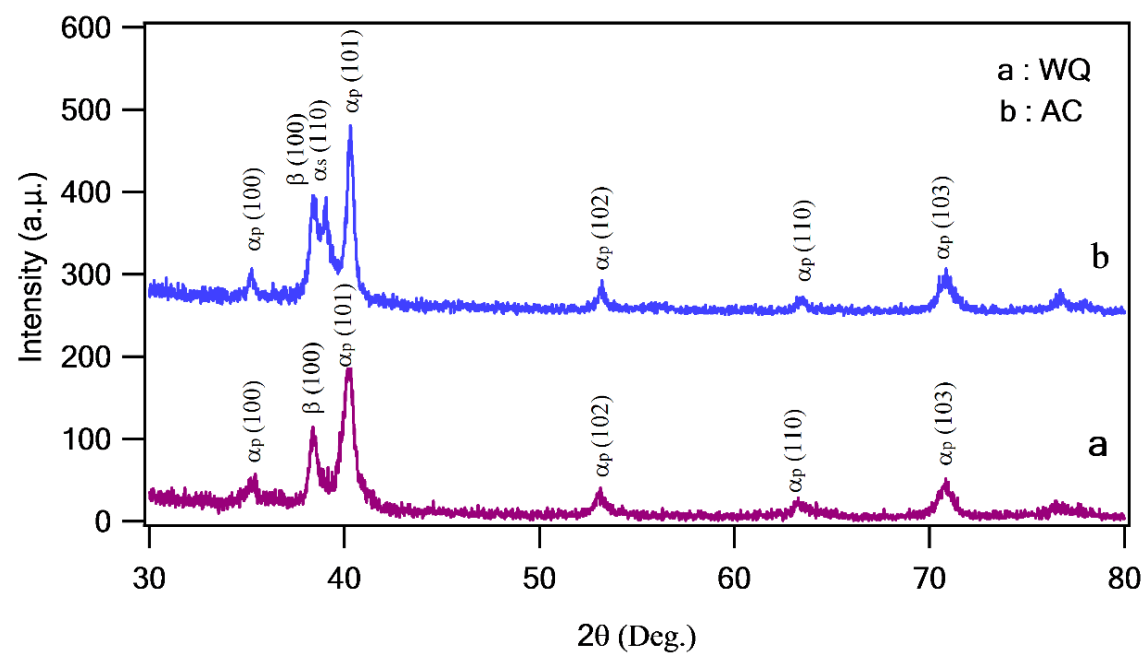

Fig. 4: X-Ray diffraction analysis for two types of microstructures. 


\subsubsection{Effect of aging treatment}

The solution plus aging treatment is considered one of the methods usually can be applied on TC21 alloy [11]. The microstructures of the as-aged samples are shown in figures 5 and 6 . The microstructures of titanium alloys are normally classified according to the morphology of $\alpha$ phase, including equiaxed, lamellar and bi-model microstructure [1]. However, $\alpha$ phase exhibits many varieties of morphologies after solution and aging treatment. Aging was applied at $575^{\circ} \mathrm{C}$ for $4 \mathrm{~h}$. Because of the solution temperature $\left(900^{\circ} \mathrm{C}\right)$ is lower than the $\beta$ transus temperature, $\mathrm{T}_{\beta},\left(960^{\circ} \mathrm{C}\right)$, equiaxed $\alpha$ phase grains in the original microstructure did not dissolve during solution or solution plus aging and thereafter they remain after aging process (figure 5).

The typical FESEM microstructures of as-aged samples, in which $\alpha_{\mathrm{p}}$ shows an equiaxed shape and distributes homogenously in the $\beta$ matrix, figure 5. For AC + Aging, the $\alpha_{s}$ with a gray contrast precipitate in the residual $\beta$ matrix due to slower cooling rate in AC and aging treatment (figure 5a). In addition, the volume fractions of $\alpha_{\mathrm{p}}$ and $\alpha_{\mathrm{s}}$ are about 52 vol. $\%$ and 25 vol. $\%$, respectively (figure 7). On the other side, WQ +Aging, the $\alpha_{\mathrm{s}}$ precipitate in the residual $\beta$ matrix due to aging treatment only (figure $5 \mathrm{~b}$ ) and the volume fractions of $\alpha_{\mathrm{p}}$ and $\alpha_{\mathrm{s}}$ are about $48 \mathrm{vol} . \%$ and 20 vol. \%, respectively. As seen in figure 8 , the cooling rate and aging treatment have not significantly effect on the grain size of $\alpha_{\mathrm{p}}$ phase for all conditions. Each phase has been verified by X-Ray diffraction analysis, as shown in figure 9. This result is in agreement with the results reported by Shao et. al [21].
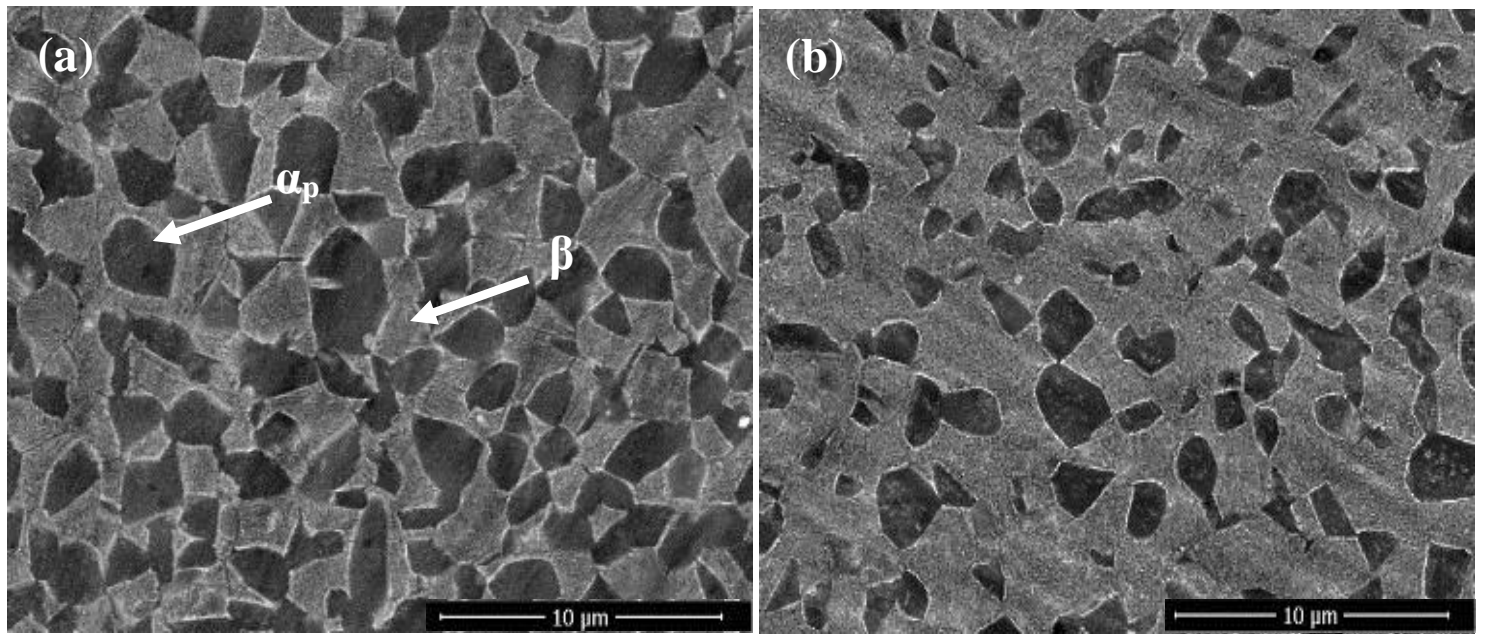

Fig. 5: FESEM images of aged samples; (a) AC +Aging and (b) WQ +Aging.

After solution treatment with two different cooling rates plus aging treatment, four types of $\alpha$ phase with different morphologies can be found: primary equiaxed $\alpha$ phase, bent lamellar (or equiaxed) $\alpha$ phase, coarse $\alpha$ plates and fine secondary $\alpha$ platelets. These four types of $\alpha$ phases form in different stages of the heat treatment processing. The primary equiaxed $\alpha$ phase exists in all conditions. The bent lamellar (even equiaxed) $\alpha$ phase will form after aging treatment, while it disappears at solution treatment only. The $\alpha$ plates form in all conditions. Finally, the fine secondary $\alpha$ platelets precipitated during aging treatment and/or cooling rate in AC. The primary equiaxed $\alpha$ phase, bent lamellar (or equiaxed) $\alpha$ phase and $\alpha$ plates are present simultaneously or individually in one 
sample. They can be seen in optical figures, so they are called "visible $\alpha$ phase" here. Fine secondary $\alpha$ platelets together with residual $\beta$ phase are called "residual $\beta$ matrix strengthened by fine secondary $\alpha$ platelets" ("residual $\beta$ matrix" for short).

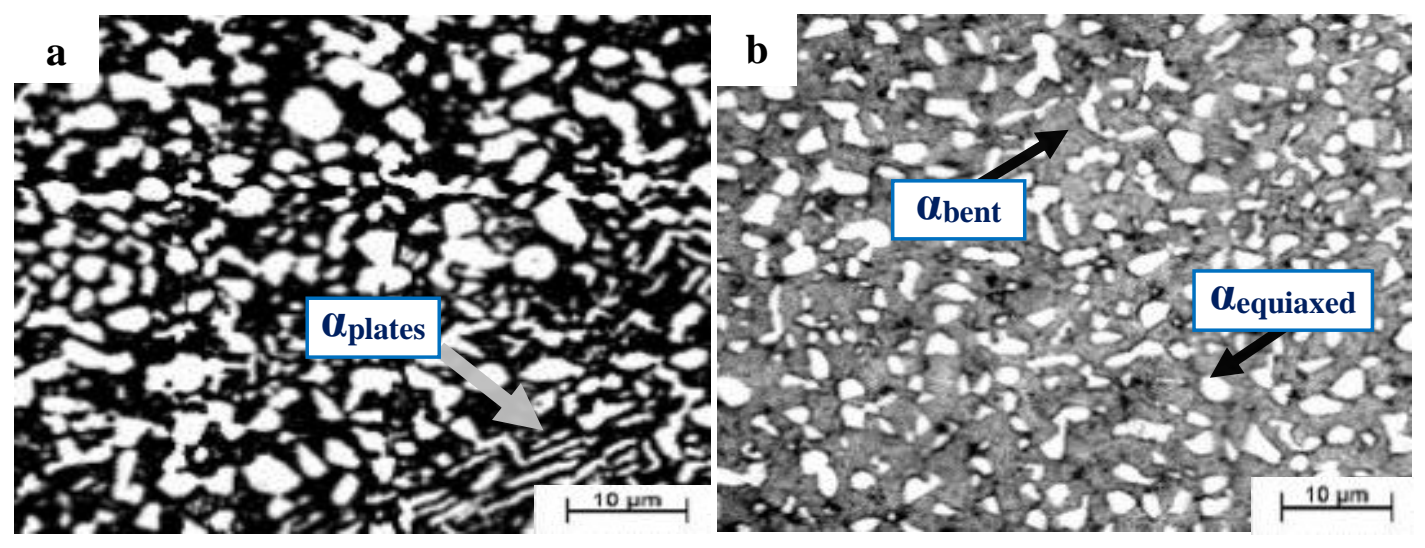

Fig. 6: Optical micrographs of aged samples: (a) AC +Aging and (b) WQ +Aging.

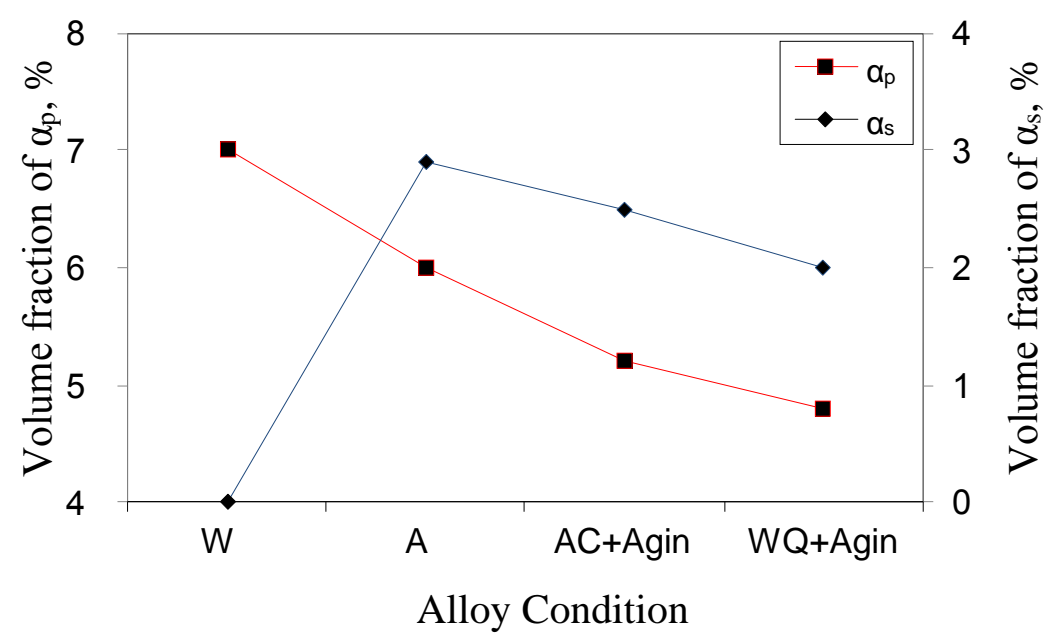

Fig. 7: Average volume fractions of $\alpha_{p}$ and $\alpha_{s}$ at various conditions.

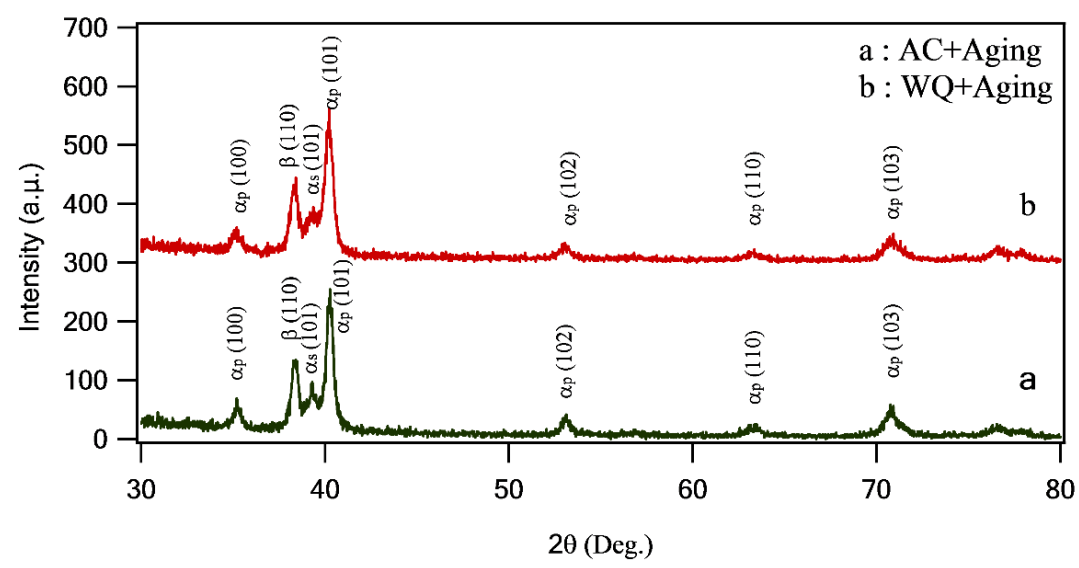

Fig. 8: X-Ray diffraction analysis for two types of microstructures. 


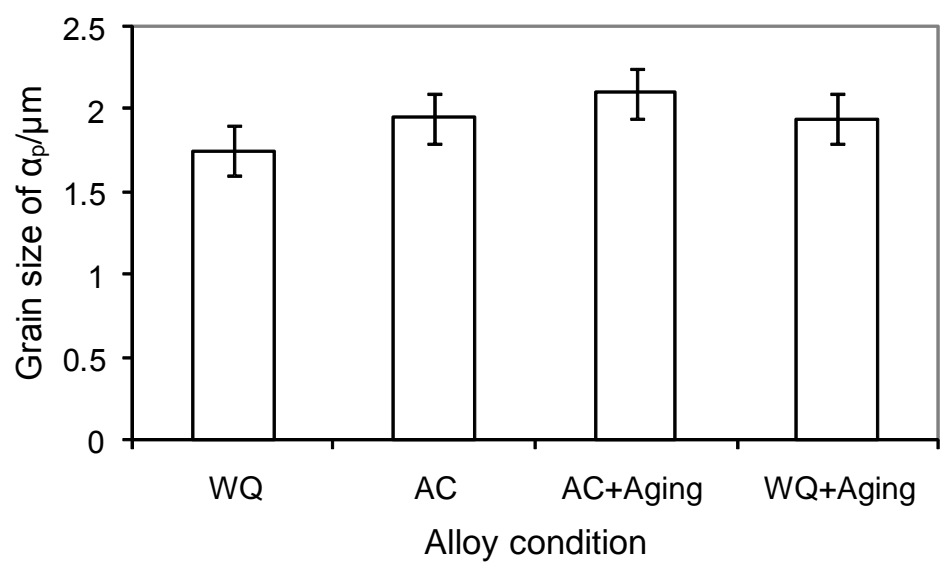

Fig. 9: Average grain size of $\alpha_{p}$ at various conditions.

\subsection{Mechanical Properties}

\subsubsection{Hardness}

The Vickers hardness measurements were carried out to investigate the influence of cooling rate and aging treatment on the as-received TC21 alloy. The results of hardness for all conditions are shown in figure 10. The WQ sample obtained the lowest hardness (HV323) due to the presence of high amount of $\alpha_{\mathrm{p}}$ phase (70\%). While, the AC sample revealed a higher hardness (HV345) compared to the WQ sample due to existing of $\alpha_{\text {s }}$ phase (secondary $\alpha$-platelets). The AC +Aging samples showed a hardness value of HV405. However, the samples WQ +Aging, obtained the highest hardness value (HV428) due to the presence of $\alpha_{\mathrm{s}}(20 \%)$ that precipitated during aging treatment as well as existing of lower amount of $\alpha_{p}$ phase (48\%) compared to the others.

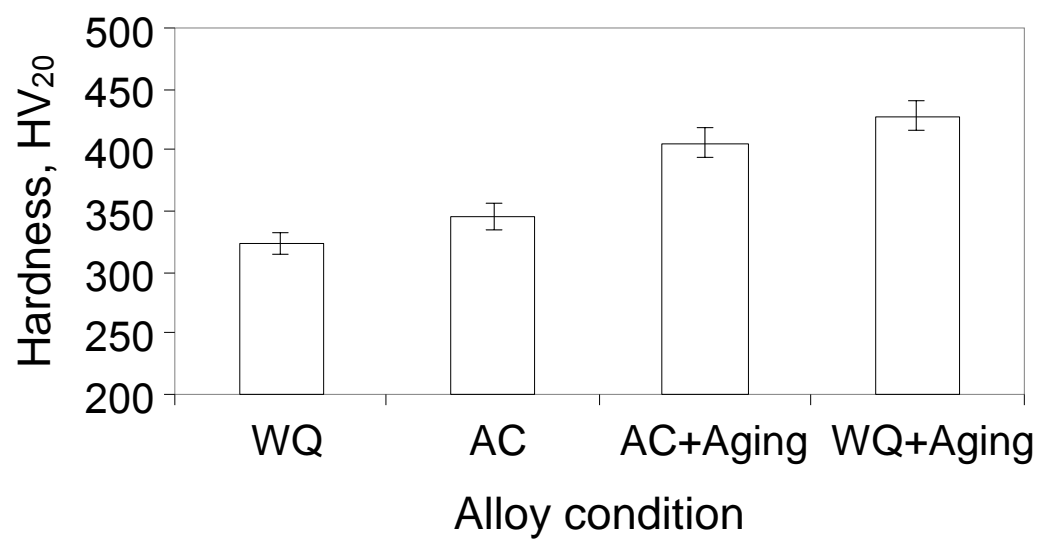

Fig. 10: Average hardness values at various conditions.

\subsubsection{Tensile properties}

The room temperature tensile properties of TC21 alloy after solution and solution plus aging treatments are shown in figure 11. It can be seen that cooling rate and aging have an important role on tensile properties of TC21 alloy. For instance, ultimate strength (UTS), yield strength (YS), elongation (El) and reduction of area (RA) obtained ranges of $1186-1480 \mathrm{MPa}, 1000-1410 \mathrm{MPa}, 6 \%-15 \%$ and $15 \%-40 \%$, respectively. Both yield and ultimate strengths increased after aging treatment on the account of ductility. The 
highest ultimate and yield strengths (1480MPa and 1410MPa respectively) were found for the case of WQ +Aging samples but at the same time this condition showed the lowest elongation and reduction of area.

The effect of $\beta$ strengthening with the $\alpha_{\mathrm{s}}$ is clearly shown for the aged samples after WQ and $\mathrm{AC}$ conditions, where the ultimate tensile strength increased from $1186 \mathrm{MPa}$ to $1480 \mathrm{MPa}$ and from $1200 \mathrm{MPa}$ to $1336 \mathrm{MPa}$, respectively. On the other hand, the elongation decreased from $15 \%$ to $6 \%$ and from $13 \%$ to $8 \%$, respectively.

As expected, the WQ + aging condition revealed the lowest elongation $(6 \%)$ and reduction of area (15\%), (figure 11b). Of course, the WQ condition obtained the highest elongation and reduction of area compared to AC because the WQ condition is characterized by low strength and hardness due to the presence of high amount of $\alpha_{\mathrm{p}}$ phase $(70 \%)$ compared to AC. The difference between ultimate tensile and yield strengths clearly increased amounting to $186 \mathrm{MPa}$ for the WQ condition and $70 \mathrm{MPa}$ in the WQ +Aging condition. On the other hand, the difference between ultimate tensile and yield strengths was estimated to be $120 \mathrm{MPa}$ in case of $\mathrm{AC}$ and $39 \mathrm{MPa}$ for $\mathrm{AC}$ +Aging condition, as illustrated in figure 11a. According to the above results, the better comprehensive mechanical properties of TC21 alloy can be obtained after AC +Aging condition for static - dynamic applications and WQ +Aging for static applications only. This finding was in agreement with the results reported by Z. F. Shi, et al. [16].
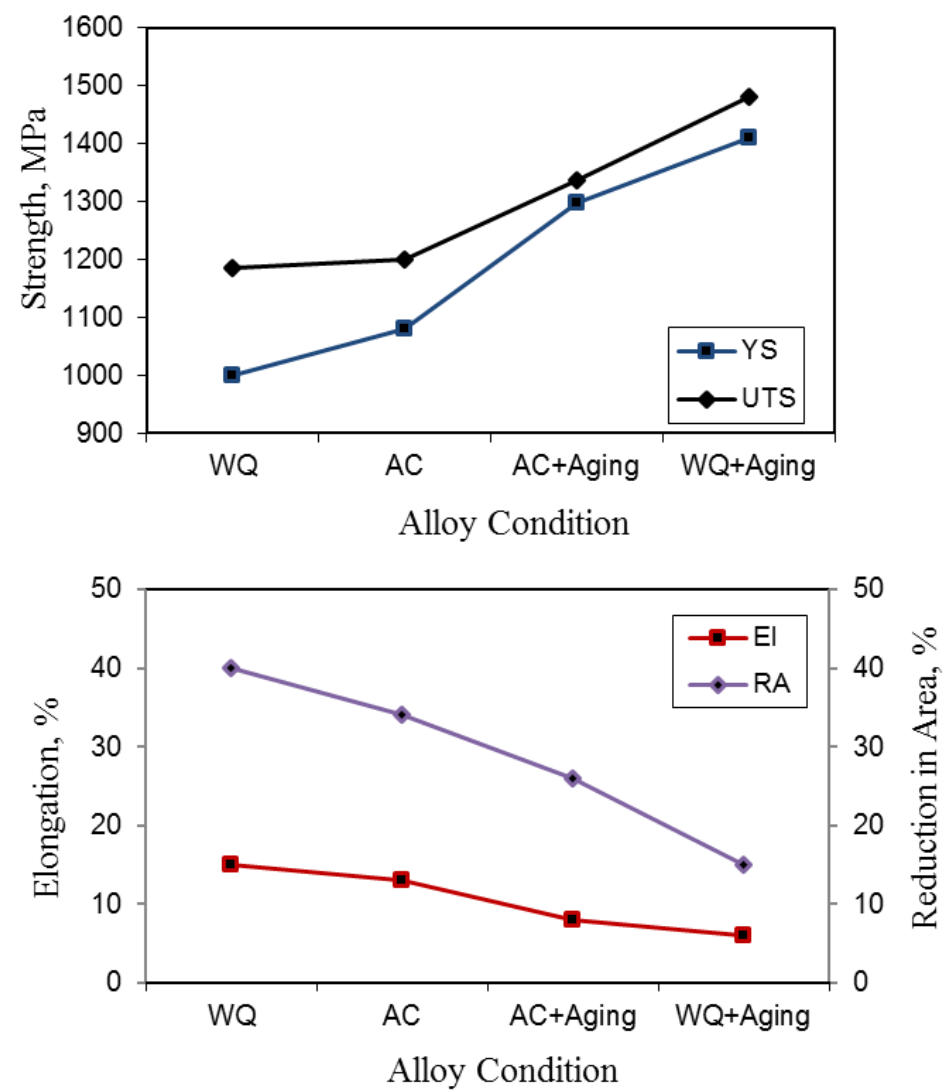

Fig. 11: Variation of UTS, YS, EI and RA at various conditions. 
The fracture surface mechanisms of WQ and AC samples are shown in figure 12. Deep and homogenous dimples were observed on the fracture surface of both studied conditions of WQ and AC. Moreover, large shrinkage, plenty of deep and big ductile dimples were noticed on the fracture surfaces of the WQ and AC conditions that prove good tensile elongation. The ductile dimples fall into two categories: (i) narrow ductile dimples, which may be induced by separation of single $\alpha$ grain or $\beta$ grain and (ii) wide ductile dimples, which may be induced, by separation of several $\alpha$ grains [20].
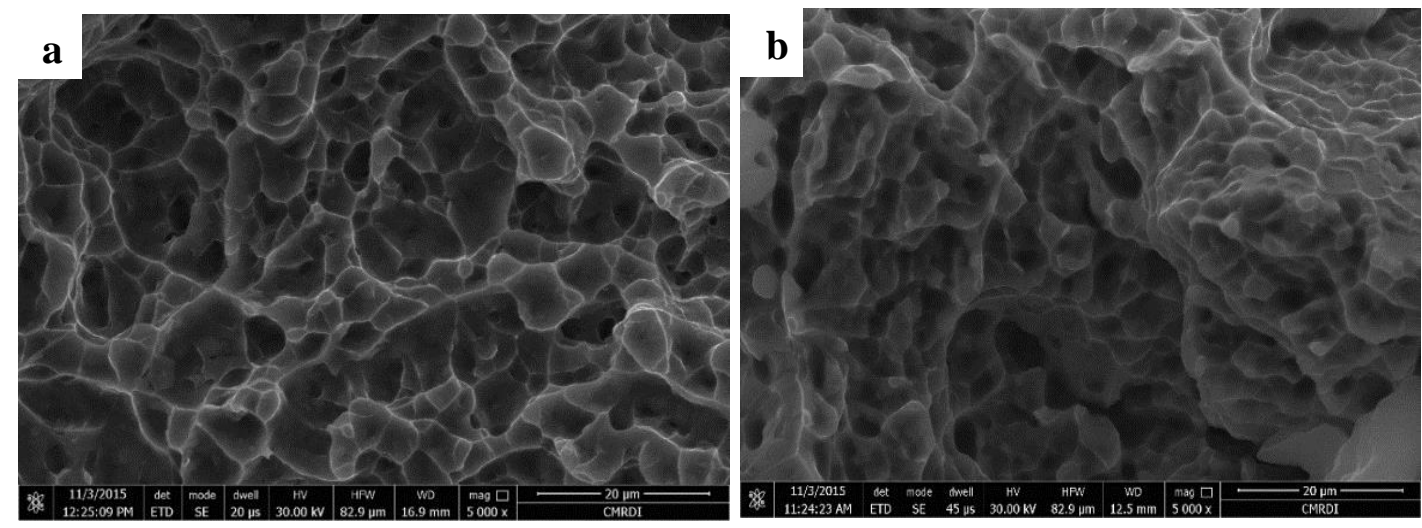

Fig. 12: Fracture surface of room tensile samples: (a) WQ and (b) AC.

The fracture mechanisms of AC +Aging and WQ +Aging conditions for room temperature tensile samples were checked by detecting the fracture morphologies as shown in figure 13. Dimpled and intergranular fracture were found, where the dimples are much smaller and shallower than those are existing in cases of AC and WQ conditions. The appearance of cleavage plane is unnegligible, and the intergranular fractured mechanism also causes a decrease in ductility. Thus, small shrinkage, small and shallow dimples existing on the fracture surfaces are in agreement with the low ductility of both AC +Aging and WQ +Aging conditions. The fracture surface of WQ +Aging samples (figure 13b) showed quasi-cleavage fracture in conjunction with some fine equiaxed dimples and flat areas resulting from the intergranular fracture of $\alpha$ grains (figure 13b). These results are in agreement with the fact that the WQ +Aging condition showed the lowest elongation $(6 \%)$.
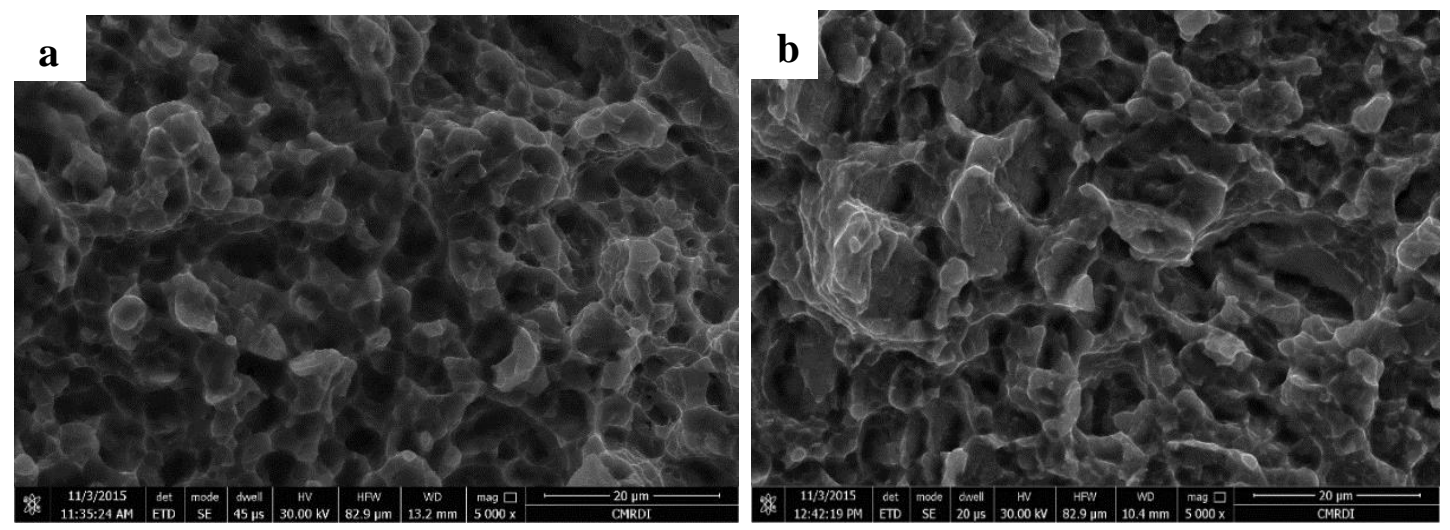

Fig. 13: Fracture surface of room tensile samples: (a) AC +Aging and (b) WQ +Aging. 


\section{Conclusions}

The effect of applying two different cooling rates and aging treatment on microstructure and tensile properties of TC21 titanium alloy was thoroughly investigated. The following conclusions can be drawn from this investigation.

- After solution treatment with two different cooling rates and aging treatment, $\alpha$ phase exhibits four types of morphologies: primary equiaxed $\alpha$ phase, bent lamellar (or equiaxed) $\alpha$ phase, $\alpha$ plates and fine secondary $\alpha$ platelets. Fine secondary $\alpha$ platelets and residual $\beta$ phase form residual $\beta$ matrix.

- Better combination of hardness and tensile properties can be achieved by $\mathrm{AC}+$ Aging condition.

- Optimal heat-treatment scheme for TC21 alloy should be applied at the $\alpha+\beta$ phase region and cooling rate of $\mathrm{AC}$ plus aging treatment.

- Tensile fractured surface morphologies for WQ condition showed equiaxed dimple feature with good ductility, and WQ +Aging condition obtained intergranular and equiaxed dimple fractured mechanism with poor ductility.

\section{REFERENCES}

[1] Lütjering, G. and Williams, J. C.: "Titanium". $2^{\text {nd }}$ edition, Springer, Berlin Heidelberg, (2007).

[2] Banerjee, D. and Williams, J. C.: "Perspectives on titanium science and technology". Acta Materialia, vol. 61, pp. 844-879, (2013).

[3] Ibrahim, K. M.; EL-Hakeem, A. M. and Elshaer, R. N.: "Microstructure and mechanical properties of cast and heat-treated Ti-6.55Al-3.41Mo-1.77Zr alloy". Transactions of nonferrous metals society of China, vol. 23, pp. 3517-3524, (2013).

[4] Lia, G.; Xia, F.; Gao, Y. and He, Y.: "Microstructure control techniques in primary hot working of titanium alloy bars: a review". Chinese journal of aeronautics, vol. 29 (1), pp. 30-40, (2016).

[5] Srinivasu, G.; Natraj, Y.; Bhattacharjee, A.; Nandy, T. K. and Nageswara, G. V. S.: "Tensile and fracture toughness of high strength $\beta$ titanium alloy, Ti-10V-2Fe-3Al, as a function of rolling and solution treatment temperatures". Materials and design, vol. 47, pp. 323-330, (2013).

[6] Shi, Z. F.; Guo, H. Z.; Qin, C.; Liang, H. Q. and Yao, Z.: "A method to determine main microstructural features influencing mechanical properties of two-phase titanium alloys". Materials science \& engineering A, vol. 611, pp. 136-141, (2014).

[7] Ling, Z. and Dong, H.: "Microstructure of TC21 titanium alloy after superplastic deformation and heat treatment". Applied mechanics and materials, vols. 275-277, pp. 1855-1858, (2013).

[8] Wang, Y. H.; Kou, H. C.; Chang, H.; Zhu, Z. S.; Zhang, F. S.; Li, J. S. and Zhou, L.: "Influence of solution temperature on phase transformation of TC21 alloy". Materials science and engineering A, vol. 508, pp. 76-82, (2009).

[9] Xing, D. D.; Xin, L. D.; Li, M. B. and Hua1, Z. X.: "Effects of pretreatment and HVOF sprayed cermet coating on fatigue properties of TC21 titanium alloy". Science China technological sciences, vol. 56, pp. 1029-1037, (2013).

[10] Wen-guang, L.; Xiao-nan, M.; Zhi-min, H.; Ya-feng, L.; Heng-lei, Q.; Yi-gang, Z. and Zheng-pin, X.: "Effect of heat treatment on microstructures and mechanical properties of TC21 alloy large bar". Titanium industry process, vol. 27, pp. 28-31, (2010). 
[11] Shi, Z. F.; Guo, H. Z.; Han, J. Y. and Yao, Z. K.: "Microstructure and mechanical properties of TC21 titanium alloy after heat treatment". Transactions of nonferrous metals society of China, vol. 23, pp. 2882-2889, (2013).

[12] Fei, Y. H.; Zhou, L.; Qu, H. L.; Zhao, Y. Q. and Huang, C. Z.: "The phase and microstructure of TC21 alloy". Material science and engineering A, vol. 494, pp. 166-172, (2008).

[13] Wang, Y. H.; Kou, H. C.; Chang, H.; Zhu, Z. S.; Zhang, F. S.; Su, X.; Li, J. S. and Zhou, L.: "Phase transformation in TC21 alloy during continuous heating". Journal of alloys and compounds, vol. 472, pp. 252-256, (2009).

[14] Zhu, Y.; Zeng, W.; Sun, Y.; Feng, F. and Zhou, Y.: "Characterization of hot deformation behavior of as-cast TC21 titanium alloy using processing map". Materials science and engineering A, vol. 528, pp. 1757-1763, (2011).

[15] Zhu, Y. C.; Zeng, W. D.; Liu, J. L.; Zhao, Y. Q.; Zhou, Y. G. and Yu, H. Q.: "Effect of processing parameters on the hot deformation behavior of as-cast TC21 titanium alloy". Materials and design, vol. 33, pp. 264-272, (2012).

[16] Shi, Z. F.; Guo, H. Z.; Liu, R.; Wang, X. C. and Yao, Z. K.: "Microstructure and mechanical properties of TC21 titanium alloy by near-isothermal forging". Transactions of nonferrous metals society of China, vol. 25, pp. 72-79, (2015).

[17] Wang, X.; Zhao, Y.; Wei, X. and Hou, H.: "Microstructures of TC21 alloys after hydrogenation and dehydrogenation". Transactions of nonferrous metals society of China, vol. 24, pp. 82-88, (2014).

[18] Jia, Z.; Zeng, W.; Zha, Y.; Shi, C.; Qua, B. and Wu, J.: "The color changes and tensile properties of oxidized Ti-6A1-2Mo-1.5Cr-2Zr-2Sn-2Nb alloy". Journal of alloys and compounds, vol. 640, pp. 488-496, (2015).

[19] Tan, C.; Li, X.; Sun, Q.; Xiao, L.; Zhao, Y. and Sun, J.: "Effect of $\alpha$-phase morphology on low-cycle fatigue behavior of TC21 alloy". International journal of fatigue, vol. 75, pp. 1-9, (2015).

[20] Li, H.; Li, M.; Luo, J. and Wang, K.: "Microstructure and mechanical properties of heat-treated Ti-5Al-2Sn-2Zr-4Mo-4Cr". Transactions of nonferrous metals society of China, vol. 25, pp. 2893-2900, (2015).

[21] Shao, H.; Zhao, Y.; Ge, P. and Zeng, W.: "Crack initiation and mechanical properties of TC21 titanium alloy with equiaxed microstructure". Materials science \& engineering A, vol. 586, pp. 215-222, (2013). 